\title{
Investigation of postoperative intraocular pressure in cases of silicone oil removal using 25-gauge transconjunctival sutureless vitrectomy with oblique incisions
}

\author{
This article was published in the following Dove Press journal: \\ Clinical Ophthalmology \\ 15 October 2015 \\ Number of times this article has been viewed
}

\author{
Hirotsugu Takashina ${ }^{1,2}$ \\ Akira Watanabe ${ }^{2}$ \\ Hiroshi Tsuneoka ${ }^{2}$ \\ 'Department of Ophthalmology, \\ National Hospital Organization \\ Sagamihara Hospital, Sagamihara, \\ Kanagawa, Japan; ${ }^{2}$ Department of \\ Ophthalmology, Jikei University \\ School of Medicine, Minato-ku, \\ Tokyo, Japan
}

Background: The purpose of this study was to investigate postoperative intraocular pressure (IOP) in cases of silicone oil (SO) removal when using 25-gauge transconjunctival sutureless vitrectomy (TSV) with oblique incisions.

Methods: We enrolled ten consecutive eyes with SO removal (SO group) and eleven consecutive eyes with idiopathic epiretinal membrane (ERM) as the initial vitrectomy (ERM group) in cases using 25-gauge TSV with oblique incisions. Postoperative IOPs were compared between the two groups at each of the four examination periods.

Results: No significant differences were identified in any of the periods examined.

Conclusion: The use of 25-gauge TSV with oblique incisions resulted in almost equivalent postoperative IOPs between cases with SO removal and idiopathic ERM as the initial operation. Self-sealing sclerotomy in 25-gauge TSV with oblique incisions may primarily involve the valve architecture, and be complemented by vitreous incarceration.

Keywords: sclerotomy leakage, self-sealing, silicone oil tamponade, remnant vitreous, hypotony, idiopathic epiretinal membrane

\section{Introduction}

In 2002, Fujii et al first reported the characteristic procedures for transconjunctival sutureless vitrectomy (TSV) and then compared the method to sutureless sclerotomy (self-sealing sclerotomy) with conventional 20-gauge vitrectomy. ${ }^{1}$ Fine et al reported that the potential advantages of TSV over conventional 20-gauge vitrectomy were faster wound healing, reduced conjunctival scarring, greater patient comfort, decreased postoperative inflammation, reduced postoperative astigmatic changes, and shorter surgical opening and closing times. ${ }^{2}$ Recently, there has been a gradual expansion of the indications for TSV, ${ }^{3}$ with silicone oil (SO) injections now used during TSV procedures for severe vitreoretinal diseases. When using SO injections, careful attention must be paid to the importance of performing a thorough vitrectomy in order to prevent severe complications such as proliferative vitreoretinopathy due to postoperative shrinkage of the remnant vitreous. ${ }^{4}$ Furthermore, the necessity of SO removal shortly after the procedure must be taken into consideration to ensure complications, such as intraocular pressure (IOP) increases due to emulsification, do not occur. ${ }^{5}$ However, postoperative shrinkage of the slight remnant vitreous that was thoroughly shaved prior to the SO injection decreases the remnant vitreous volume after SO injection surgery, and thus may lead to little vitreous incarceration in the sclerotomy. Because
Correspondence: Hirotsugu Takashin Department of Ophthalmology, jikei University School of Medicine, 3-19-I 8 Nishi-shinbashi, Minato-ku, Tokyo 105-847I, Japan

Tel +8I 33433 I I I I ext 358 I

Fax +8I 334331936

Email two-shina@s7.dion.ne.jp 
vitreous incarceration to the sclerotomy is one of the factors that influences self-sealing sclerotomy, ${ }^{6}$ the risk of postoperative IOP decrease due to sclerotomy leakage is more likely in cases of SO removal. Therefore, special consideration of the postoperative IOP is needed in cases of SO removal when using TSV. This study was designed to examine the postoperative IOP in cases of SO removal when using 25-gauge TSV with oblique incisions.

\section{Patients and methods}

This is a retrospective study and therefore patient consent was not needed. This study was approved by the Institutional Committee of the National Hospital Organization of Sagamihara Hospital, and complied with the tenets of the Declaration of Helsinki. We enrolled ten pseudophakic eyes of ten consecutive patients who underwent SO removal following an SO (SILIKON1000 ${ }^{\circledR}$; Alcon Laboratories, Inc., Fort Worth, TX, USA) injection that was performed during 25-gauge TSV (SO group), and eleven pseudophakic eyes of eleven consecutive idiopathic epiretinal membrane (ERM) patients who received an initial vitrectomy (ERM group) at the National Hospital Organization of Sagamihara Hospital from May 2013 to August 2014. Patients who underwent a buckle procedure or gas tamponade or involved history of glaucoma were excluded. The same surgeon $(\mathrm{HT})$ performed each surgery using an Alcon 25-gauge system (TOTAL PLUS $^{\circledR} /$ Viscous Fluid Control Pak $^{\circledR} /$ Constellation $^{\circledR}$; Alcon Laboratories) and a wide-angle viewing system (Resight ${ }^{\circledR}$; Carl Zeiss, San Leandro, CA, USA). Because several articles have reported that the use of oblique incision promotes sclerotomy self-sealing due to the valve architecture, ${ }^{7-9}$ sclerotomies were made vertical to the limbus at an angle of $45^{\circ}$ to the sclera (oblique incision) and cannulas were placed $3.5 \mathrm{~mm}$ posterior to the limbus using the 25-gauge EDGEPLUS $^{\circledR}$ trocar/cannula system (Alcon Laboratories).

The sclerotomy for the intraocular infusion (infusion site) was performed in the inferotemporal quadrant, while the sclerotomies for the intraocular manipulations that included the use of a pneumatic vitreous cutter, endolaser probe, and endoilluminator (manipulation sites) were made in the superonasal and superotemporal quadrants. Amato and Akduman previously examined vitrectomized eyes and reported finding weakness in the self-sealing sclerotomy. ${ }^{6}$ However, our previous study indicated that there was no significant correlation between the history of vitrectomy and the degree of difficulty of self-sealing. ${ }^{10}$ Thus, in the SO group, we positioned the sclerotomies so that they avoided the sclerotomy scar of any previous vitrectomy. When removing the SO, we confirmed the remnant vitreous, and if necessary, performed vitreous shaving in this group. In contrast, we initially performed minimal peripheral vitrectomy (no vitreous incarceration to the point of the intraocular cannula) in the ERM group, with idiopathic ERM and inner limiting membrane peeling subsequently performed. Scleral massage was performed at the end of each surgery to allow self-sealing of the sclerotomy. Successful self-sealing sclerotomy was defined as the absence of increasing bleb formations and a normal IOP as checked by a tactile examination. If these conditions were not met, then we placed a suture at the sclerotomy. Postoperative IOP on day 1 (POD1) and day 2 (POD2) was measured by a Goldmann applanation tonometer. On the other hand, postoperative IOP on week 1 (POW1) and month 1 (POM1) was measured by a non-contact tonometer (TONOREFII; Nidek, Aichi, Japan), and measured again by Goldmann applanation tonometer if the IOP was less than $10 \mathrm{mmHg}$ or more than $20 \mathrm{mmHg}$. A Student's $t$-test was used to compare the factors (age, surgical time, and axial length) between the two groups, while the postoperative IOPs between the two groups at POD1, POD2, POW1, and POM1 were compared using either a repeated measures analysis of variance or a Student's $t$-test. Statistical analyses were performed using software programmed by Hisae Yanai (Statcel-3; OMS Publication, Saitama, Japan) along with the Excel software program (Microsoft Corporation, Redmond, WA, USA). $P$-values $<0.05$ were considered as statistically significant.

\section{Results}

None of the sclerotomies required any suture placement. The mean duration of the SO tamponade was 3.1 1.4 months in the SO group. Table 1 summarizes the mean values for each of the factors. Significant differences between the two groups were identified for age and surgical time, but not for axial length. There was no need to perform vitreous shaving in the SO group. Additional procedures required in the SO group included inner limiting membrane peeling (three cases) and photocoagulation (three cases). There were no additional

Table I The mean values of each factor

\begin{tabular}{llll}
\hline & Age (years) & $\begin{array}{l}\text { Surgical time } \\
\text { (minutes) }\end{array}$ & $\begin{array}{l}\text { Axial length } \\
(\mathbf{m m})\end{array}$ \\
\hline SO group & $61.7 \pm 12.4$ & $36.2 \pm 8.2$ & $23.9 \pm 1.5$ (range \\
& $($ range 39-77) & (range 26-53) & $22.05-26.92)$ \\
ERM group & $74.9 \pm 7.7$ & $23.8 \pm 1.8$ & $26.2 \pm 6.2$ (range \\
& $($ range 62-86) & $($ range 19-39) & $21.36-28.14)$ \\
P-value & $<0.05^{*}$ & $<0.05^{*}$ & 0.88 \\
\hline
\end{tabular}

Notes: Data are expressed as mean \pm standard deviation. $* P<0.05$. Abbreviations: SO, silicone oil; ERM, epiretinal membrane. 
Table 2 The mean values of postoperative intraocular pressure

\begin{tabular}{|c|c|c|c|c|}
\hline & PODI (mmHg) & POD2 (mmHg) & POWI (mmHg) & POMI (mmHg) \\
\hline SO group & 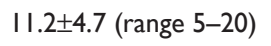 & $10.4 \pm 3.1$ (range 6-14) & $14.0 \pm 4.0$ (range 10-23) & $14.4 \pm 2.5$ (range II-18) \\
\hline ERM group & $10.1 \pm 3.8($ range $5-14)$ & $10.5 \pm 2.9($ range $7-16)$ & $14.1 \pm 3.9$ (range 6-22) & 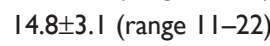 \\
\hline$P$-value & 0.21 & 0.94 & 0.92 & 0.58 \\
\hline
\end{tabular}

Note: Data are expressed as mean \pm standard deviation.

Abbreviations: SO, silicone oil; ERM, epiretinal membrane; PODI, postoperative day I; POD2, postoperative day 2; POWI, postoperative week I; POMI, postoperative month I.

procedures required for the ERM group. Table 2 summarizes the mean values of the postoperative IOP. There were no cases of hypotony (defined as an IOP less than $5 \mathrm{mmHg}$ ) and no significant differences in the postoperative IOP identified at any of the observational periods. Table 3, which summarizes the analysis of variance statistical data, shows that there was a significant difference for the variation within the subgroup, but not for either the interaction or the variation between the subgroups.

\section{Discussion}

In the present study, all sclerotomies were considered to be self-sealed without remarkable sclerotomy leakage after POD1, as none of the patients experienced any postoperative hypotony and bleb formations. However, Kapran and Acar previously detected a decrease in the IOP at 2 hours postoperatively and speculated that this finding was due to a subclinical amount of leakage, ${ }^{11}$ and Yamane et al reported a finding that the ciliochoroidal detachment was caused by hypotony that occurred on the day of the surgery, which suggested that postoperative hypotony might cause a reduction of the aqueous formation secondary to the ciliochoroidal detachment. ${ }^{12}$ Based on these previous results, we postulated that the postoperative IOP in the SO group would be lower than that observed in the ERM group since there is little, if any, vitreous incarceration associated with the sclerotomy in the $\mathrm{SO}$ as compared with the ERM group. However, we found no significant differences between the SO and ERM groups for the postoperative IOP at each of the observation periods and for the variation between the subgroups. These findings may indicate that the existence of remnant vitreous does not have any influence on the IOP postoperatively. As a result, self-sealing sclerotomies in 25-gauge TSV with

Table 3 Statistical data using ANOVA

\begin{tabular}{llll}
\hline & $\boldsymbol{F}$-value & $\boldsymbol{P}$-value & $\boldsymbol{F ( 0 . 9 5 )}$ \\
\hline Interaction & 1.53 & 0.22 & 2.76 \\
Variation between subgroups & 0.04 & 0.84 & 4.35 \\
Variation within subgroup & 24.36 & 0.00 & 2.76 \\
\hline
\end{tabular}

Abbreviation: ANOVA, analysis of variance. oblique incisions may primarily involve the valve architecture and be complemented by vitreous incarceration. Age, ${ }^{13,14}$ surgical time, ${ }^{7}$ and axial length ${ }^{15}$ have been reported as risk factors that can influence self-sealing sclerotomy in TSV. Although we demonstrated a significant difference for age between the two groups, with the exception of one 39-year-old patient, all of the patients were 50 years of age or older in our current study. Scleral stiffness increases with aging, ${ }^{16}$ and thus, with moderate scleral stiffness, the valve architecture is easier to restore when using scleral massage. Therefore, although a significant difference was identified for age in our study, verification of the self-sealed sclerotomies based on only the valve architecture could be done because of the sufficient scleral stiffness. Tahiri et al previously demonstrated that surgeries of long duration influenced early postoperative decrease in the IOP ${ }^{17}$ In general, surgical times for SO removal or idiopathic ERM are shorter than for severe vitreo-retinal diseases such as proliferative diabetic retinopathy or proliferative vitreoretinopathy, as thorough vitrectomies are not usually necessary in these cases. Although our study did find a significant difference for the surgical time, our determination of a self-sealed sclerotomy based on only the valve architecture in both groups might have been related to the short surgical time. On the other hand, the significant difference in the variation within the subgroup implies that the variation of the IOP existed postoperatively, thereby indicating that the existence of ciliary detachment could have been caused by subclinical amounts of leakage in this study.

Limitations in this study include the small sample size that was related to the infrequent use of SO during normal surgical procedures. Second, the existence of vitreous incarceration to the sclerotomy was not entirely accurate. However, since there was little remnant vitreous that could be shaved in the SO group, this does suggest that there was a great difference in the remnant vitreous volume between the two groups. Third, the IOP was measured only by tactile examination at the end of surgery. This could have introduced subjective inaccuracies in accordance with the judgment of the surgeon. 


\section{Conclusion}

In conclusion, when using 25-gauge TSV with oblique incisions, an almost equivalent postoperative IOP was observed between cases of SO removal and cases where the initial operation involved idiopathic ERM, and the self-sealing sclerotomy in 25-gauge TSV may involve the valve architecture of the oblique incision and hardly need vitreous incarceration.

\section{Author contributions}

Hirotsugu Takashina carried out all the surgeries, performed the statistical analysis, participated in the sequence alignment, and drafted the manuscript. Akira Watanabe and Hiroshi Tsuneoka participated in its design and coordination and helped to draft the manuscript. All authors read and approved the final manuscript.

\section{Disclosure}

The authors report no conflicts of interest in this work.

\section{References}

1. Fujii GY, De Juan E Jr, Humayun MS, et al. Initial experience using the transconjunctival sutureless vitrectomy system for vitreoretinal surgery. Ophthalmology. 2002;109(10):1814-1820.

2. Fine HF, Iranmanesh R, Iturralde D, Spaide RF. Outcomes of 77 consecutive cases of 23-gauge transconjunctival vitrectomy surgery for posterior segment disease. Ophthalmology. 2007;114(6):1197-1200.

3. Shimada H, Nakashizuka H, Mori R, Mizutani Y. Expanded indications for 25-gauge transconjunctival sutureless vitrectomy. Jpn JOphthalmol. 2005;49(5):397-401.

4. Song Y, Shin YW, Lee BR. Adjunctive use of a novel releasable suture technique in transconjunctival vitrectomy. Retina. 2011;31(2):243-249.

5. Toklu Y, Cakmak HB, Ergun SB, Yorgun MA, Simsek S. Time course of silicone oil emulsification. Retina. 2012;32(10):2039-2044.
6. Amato JE, Akduman L. Incidence of complications in 25-gauge transconjunctival sutureless vitrectomy based on the surgical indications. Ophthalmic Surg Lasers Imaging. 2007;38(2):100-102.

7. Lin AL, Ghate DA, Robertson ZM, O'Sullivan PS, May WL, Chen CJ. Factors affecting wound leakage in 23-gauge sutureless pars plana vitrectomy. Retina. 2011;31(6):1101-1108.

8. Shimozono M, Oishi A, Kimakura H, Kimakura M, Kurimoto Y. Threestep incision for 23-gauge vitrectomy reduces postoperative hypotony compared with an oblique incision. Ophthalmic Surg Lasers Imaging. 2011;42(1):20-25.

9. Shimada H, Nakashizuka H, Mori R, Mizutani Y, Hattori T. 25-gauge scleral tunnel transconjunctival vitrectomy. Am J Ophthalmol. 2006; 142(5):871-873.

10. Takashina H, Watanabe A, Mitooka K, Tsuneoka H. Examination of selfsealing sclerotomy for vitrectomized eye under gas tamponade in 23-gauge transconjunctival sutureless vitrectomy. Semin Ophthalmol. 2014;24: $1-5$.

11. Kapran Z, Acar N. Removal of silicone oil with 25-gauge transconjunctival sutureless vitrectomy system. Retina. 2007;27(8):1059-1064.

12. Yamane S, Inoue M, Arakawa A, Kadonosono K. Early postoperative hypotony and ciliochoroidal detachment after microincision vitrectomy surgery. Am J Ophthalmol. 2012;153(6):1099-1103.

13. Byeon SH, Lew YJ, Kim M, Kwon OW. Wound leakage and hypotony after 25-gauge sutureless vitrectomy: factors affecting postoperative intraocular pressure. Ophthalmic Surg Lasers Imaging. 2008;39(2): 94-99.

14. Byeon SH, Chu YK, Lee SC, Koh HJ, Kim OW, Kwon OW. Problems associated with the 25-gauge transconjunctival sutureless vitrectomy system during and after surgery. Ophthalmologica. 2006;220(4):259-265.

15. Woo SJ, Park KH, Hwang JM, Kim JH, Yu YS, Chung H. Risk factors associated with sclerotomy leakage and postoperative hypotony after 23-gauge transconjunctival sutureless vitrectomy. Retina. 2009;29(4): 456-463.

16. Friberg TR, Lace JW. A comparison of the elastic properties of human choroid and sclera. Exp Eye Res. 1988;47(3):429-436.

17. Tahiri Joutei Hassani R, El Sanharawi M, Adam R, Monin C, DupontMonod S, Baudouin C. Influence of sutureless 23-gauge sclerotomy architecture on postoperative intraocular pressure decrease: results of a multivariate analysis. Graefes Arch Clin Exp Ophthalmol. 2013;251(5): 1285-1292.
Clinical Ophthalmology

\section{Publish your work in this journal}

Clinical Ophthalmology is an international, peer-reviewed journal covering all subspecialties within ophthalmology. Key topics include: Optometry; Visual science; Pharmacology and drug therapy in eye diseases; Basic Sciences; Primary and Secondary eye care; Patient Safety and Quality of Care Improvements. This journal is indexed on
Dovepress

PubMed Central and CAS, and is the official journal of The Society of Clinical Ophthalmology (SCO). The manuscript management system is completely online and includes a very quick and fair peer-review system, which is all easy to use. Visit http://www.dovepress.com/ testimonials.php to read real quotes from published authors. 